\title{
Ambient Vibration Measurement Data of a Four-Story Mass Timber Building
}

\author{
Ignace Mugabo ${ }^{1,2}$, Andre R. Barbosa ${ }^{1 *}$, Mariapaola Riggio ${ }^{2}$ and James Batti ${ }^{1}$ \\ ${ }^{1}$ School of Civil and Construction Engineering, Oregon State University, Corvallis, OR, United States, ${ }^{2}$ Department of Wood \\ Science and Engineering, Oregon State University, Corvallis, OR, United States
}

Keywords: ambient vibration testing, cross-laminated timber, light-frame construction, mass timber construction, operational modal analysis

\section{INTRODUCTION}

Ambient vibration from wind, traffic, and human activities results into low levels of building motion. As a result, ambient vibration collected data have been used to extract dynamic characteristics of a wide array of civil engineering structures. Among these, a few dynamic characterization tests have been performed on timber building structures, but only a few focused on mass timber structures using different types of engineered wood products for the gravity and/or lateral load resisting systems (Worth et al., 2012; Reynolds et al., 2015, 2016). Since there is a growing interest in design and construction of mass timber structures for multi-story buildings,

OPEN ACCESS

Edited by:

Eleni N. Chatzi,

ETH Zürich, Switzerland

Reviewed by:

Hilmi Luş,

Bogaziçi University, Turkey

Shinta Yoshitomi,

Ritsumeikan University, Japan Irwanda Laory,

University of Warwick,

United Kingdom

*Correspondence:

Andre R. Barbosa

Andre.Barbosa@oregonstate.edu

Specialty section:

This article was submitted to

Structural Sensing,

a section of the journal

Frontiers in Built Environment

Received: 25 January 2019

Accepted: 07 May 2019

Published: 22 May 2019

Citation:

Mugabo I, Barbosa AR, Riggio M and

Batti J (2019) Ambient Vibration

Measurement Data of a Four-Story

Mass Timber Building.

Front. Built Environ. 5:67.

doi: 10.3389/fbuil.2019.00067 it is important to provide dynamic data obtained from actual constructed projects.

The dynamic features of buildings have lead researchers and design professionals to gain knowledge of how structures behave under ambient excitations offering guidance on serviceability performance and insights on the structural performance of structures under high winds and seismic loading. Serviceability performance are of particular relevance for mass timber buildings when compared to conventional concrete and steel buildings, due to the lack of available data. Dynamic data for this type of building is necessary to understand the influence of overall mass, stiffness, and mass distribution on the modal parameters of the structure (frequencies, damping, and mode shapes), especially. The availability of these data can contribute to the effective design of mass timber buildings to ambient and wind-induced vibrations and the consequent occupant comfort and safety.

In the past decade, cross-laminated timber (CLT) has been adopted for structural assemblies of some North American multi-story buildings. One of these projects is the "Albina Yard," a fourstory building located in Portland, OR, which is the first multi-story construction built using U.S. manufactured cross-laminated timber (CLT) floor systems. There is currently a lack of open-access test data on existing buildings using mass timber technology. This study addresses this research need. Ambient vibration data were collected on the "Albina Yard," providing one of the few dynamic dataset for a U.S. building constructed using CLT members. An application and discussion of these data using two operational modal analysis (OMA) methods is presented in Mugabo et al. $(2019)^{1}$. In the cited study, dynamic characteristics of the Albina Yard building were obtained, using the Enhanced Frequency Domain Decomposition (EFDD; Brincker et al., 2001) and the Stochastic Subspace Identification (SSI; Brincker and Andersen, 2006) methods. However, other OMA approaches could be used and results compared to those presented in Mugabo et al. (2019) ${ }^{1}$. In addition, these collected data can be used for benchmarking future finite element modeling to estimate building performance under extreme loading. For this reason, the complete dynamic dataset for the Albina Yard building is provided to the wider research community for further investigation and dynamic data analyses.

\footnotetext{
${ }^{1}$ Mugabo, I., Barbosa, A. R., and Riggio, M. (2019). Dynamic characterization and vibration analysis of a four-story mass timber building. Submitted to Frontiers in Built Environment.
} 


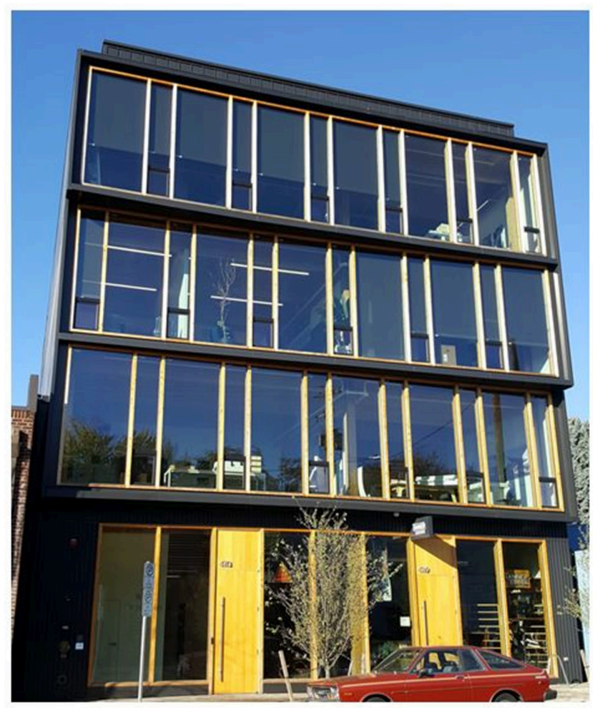

A

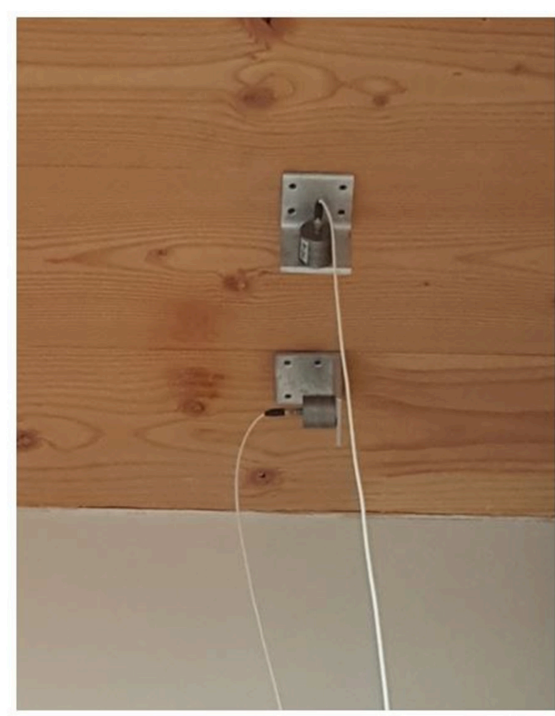

B

FIGURE 1 | (A) Photo of the "Albina Yard" taken from the East side of the building. (B) Photo showing two uni-axial accelerometers with aluminum-coated brackets attached to the CLT floor.

This data report aims at guiding interested parties to the dataset and providing essential information for understanding the data. Value and use of the data are listed below:

- The data can be directly used to perform output-only modal identification of the investigated structure.

- The data can be compared to future dynamic data of the same building, to investigate possible variation of modal properties of the structure with time.

- The data can be compared to data acquired on other mass timber buildings.

- The data can be used to benchmark finite element models of the same building.

\section{DESCRIPTION OF DATASET}

The "Albina Yard" building has approximately $27.20 \times 13.95 \mathrm{~m}$ of plan area per floor and a total height of approximately $15.39 \mathrm{~m}$ over four stories. The gravity load bearing system consists of Douglas-Fir (DF - Pseudotsuga menziesii) cross-laminated timber (CLT) floors supported on DF glued laminated (glulam) timber frames. Light-frame double-sheathed shear walls are used for the lateral force resisting system. The building envelope is comprised mainly of window glazing on the East and West façades and metal cladding walls on the North and South faces. Figure 1A presents a view of the building's eastern side. Drawings of the tested building can be found in the dataset described below. More information on the structural details is presented in Mugabo et al. (2019) ${ }^{1}$.

The dynamic data collection took place in January 2017 shortly after the building was commissioned. Data were collected a weekend day to avoid interference with occupants' activities and minimize the input from human-induced vibrations. The building was tested assuming ambient conditions (vibration from external environmental sources, such as road traffic, wind, etc.). Approximately $2 \mathrm{~h}$ of ambient acceleration data were collected using 16 uni-axial accelerometers (Figure 1B) and one tri-axial accelerometer. The uniaxial accelerometers have $\sim 1,000 \mathrm{mV} / \mathrm{g}$ sensitivity, acceleration measurement range of $\pm 5 \mathrm{~g}$ peak, a frequency range of 0.06 to $450 \mathrm{~Hz}$, and a broadband resolution 0.000003 g root mean square (RMS). The tri-axial accelerometer has $\sim 100 \mathrm{mV} / \mathrm{g}$ sensitivity, acceleration measurement range of $\pm 50 \mathrm{~g}$ peak, a frequency range of $0.6-5,000 \mathrm{~Hz}$, and broadband resolution $0.0002 \mathrm{~g}$ RMS. For the tri-axial accelerometer, only the measurements corresponding to the horizontal directions were measured. The accelerometers were connected through coaxial cables (with a resistivity of $50 \mathrm{Ohms}$ ) to a portable data acquisition system (National Instruments, NI cDAQ - 9174), which transmitted the data to a laptop computer with NI Labview SignalExpress 2014 software (National Instruments, 2013). Asrecorded raw data, without any filtering, are included in the presented dataset.

Overall, on each floor level, vibration measurements were taken at the northwestern corner (between farthest beam to column connection and drywall), center point (utility room closet), and/or southeastern corner of the building (between farthest beam to column connection and wall). The utility room is not at the geometric center of mass of the floor plan of the building; however, it is estimated to be the closest accessible location to the planar center of mass. At each of these three locations, acceleration values were taken in the EW and NS directions of the building plan.

Data collection were conducted in two setups: setup 1 and setup 2. In setup 1, the accelerometers were attached on the 


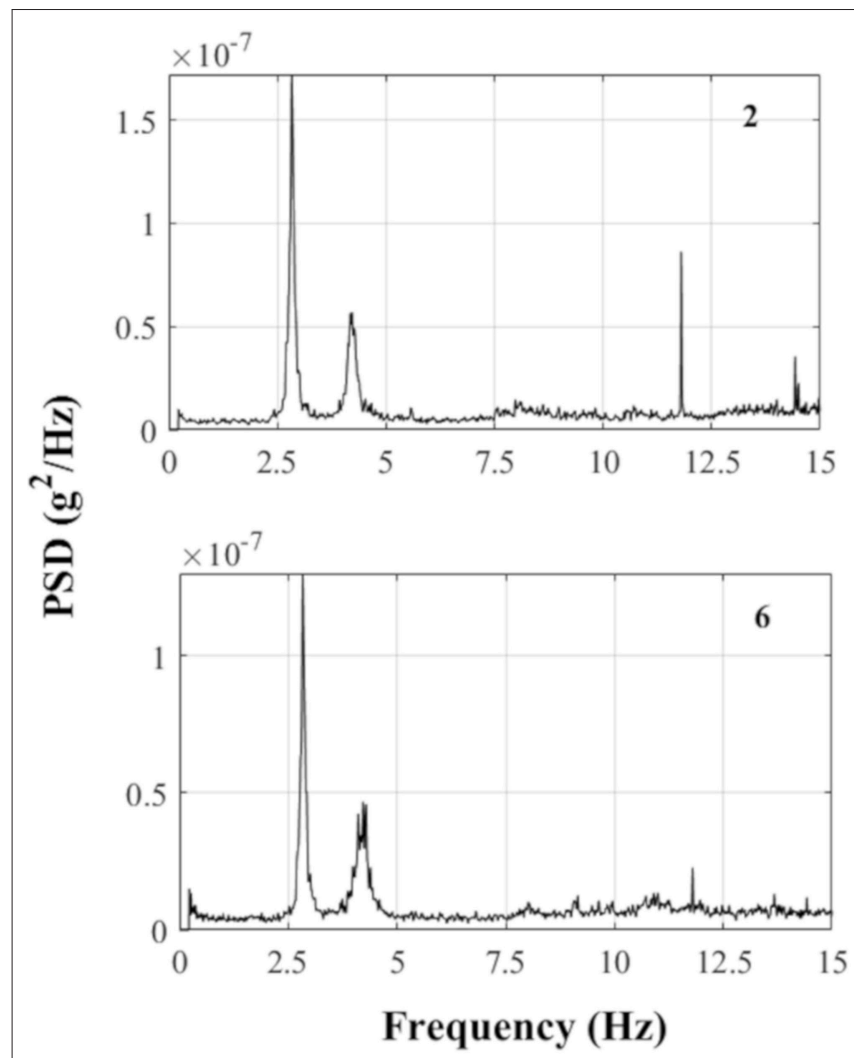

FIGURE 2 | Power spectral densities of channels 2 and 6 acceleration data taken during setup 1.

underside of the roof, fourth floor, and third levels. During setup 2 , four accelerometers were moved from the fourth level to the second level. The remaining accelerometers shared the same locations for both setups. It is worth noting that the northwestern corner of the second floor level was not instrumented because it was not accessible during the testing period. For each setup, the data were collected for $\sim 1 \mathrm{~h}$, with a sampling frequency of $2,048 \mathrm{~Hz}$. Figure 2 is provided to highlight the quality of the data based on two channels labeled channel 2 and 6 taken during setup 1. The channels 2 and 6 measured the NS accelerations of the roof's northwestern and southeastern corners, respectively.

The dataset has the following digital object identifier ${ }^{2}$ and is accessible for download to the general public. The dataset is named "Albina Yard Building Structural Monitoring and Behavior Dataset" and is located on the Open Science Framework repository. Two main folders can be found at this repository: one for the collected data, and the other for the supporting setup information. The collected data folder, denoted as "Ambient Vibration Acceleration Data" contains two zipped files, one for each setup. The "Supporting Information" folder contains floor and elevation sketches showing the locations of the accelerometers, and a file with coordinates of the accelerometer's locations in relation to a column located at the SW corner of the

${ }^{2}$ https://doi.org/10.17605/OSF.IO/34UB6 building. The "Supporting Information" folder also contains six figures that present power spectral densities of all the channels' acceleration data taken during setup 1. The dataset contains a metadata file that provides units and abbreviations, a general data description, folder hierarchy, and data files information by line.

\section{POTENTIAL USES}

The dataset can be used for a variety of purposes related to the field of operational modal analysis (OMA). Previous operational modal analysis using these data were conducted by Mugabo et al. (2019) using two OMA methods: the enhanced frequency domain decomposition, and the stochastic subspace identification. The data can be analyzed using the many available OMA methods (Reynders, 2012). Several tasks could be of interest to researchers using these data. Studying optimal sensors locations and mechanical vibration induced noise are some among the tasks that can be of interest to researchers in regard to these data. In addition, these data can be used to support finite element model development and updating, since building information is also provided and included in Mugabo et al. (2019) ${ }^{1}$.

\section{AUTHOR CONTRIBUTIONS}

The data described in this report are related to a series of experiments devised within the framework of a multiscale research project-SMART-CLT, aimed to establish a holistic performance-monitoring protocol for mass timber buildings. The project was led by $\mathrm{MR}$, with co-Pi $\mathrm{AB}$ as main expert on dynamic monitoring. IM is, at the time of writing, a Ph.D. candidate in a dual major in Civil Engineering and Wood Science at Oregon State University. IM is co-advised by $\mathrm{AB}$ and $\mathrm{MR}$. The experimental study conducted at Albina Yard will also be part of his Ph.D. thesis titled Multiscale Dynamic Monitoring and Behavior of Cross-Laminated Timber Elements and Systems. JB participated in the design of the experimental setup, troubleshooting, and in data collection. All authors participated in the design of the dynamic monitoring plan and sensor setup, and in the data acquisition phase.

\section{FUNDING}

Funding for this study was provided by the U.S. Department of Agriculture Agricultural Research Service (USDA ARS) Agreement No. 58-0202-5-001 through the TallWood Design Institute at Oregon State University. This study was also funded by the McIntire Stennis project (contract number 1009740) provided by the National Institute of Food and Agriculture, U.S. Department of Agriculture. The first author received a Graduate Teaching Assistantship from the School of Civil and Construction Engineering at Oregon State during the year in which data collection was conducted. 


\section{ACKNOWLEDGMENTS}

The authors would like to acknowledge the individuals who helped with the data collection namely Dr. Rajendra

\section{REFERENCES}

Brincker, R., and Andersen, P. (2006). "Understanding stochastic subspace identification," in Proceeding 24th IMAC. St. Louis, MO, 279-311.

Brincker, R., Zhang, L., and Andersen, P. (2001). Modal identification of outputonly systems using frequency domain decomposition. Smart Mater. Struct. 10, 441-445. doi: 10.1088/0964-1726/10/3/303

National Instruments (2013). SignalExpress: Getting Started with SignalExpress. Austin, TX. Available online at: http://www.ni.com/pdf/manuals/373873h.pdf

Reynders, E. (2012). System identification methods for (operational) modal analysis: review and comparison. Arch. Comput. Methods Eng. 19, 51-124. doi: 10.1007/s11831-012-9069-x

Reynolds, T., Casagrande, D., and Tomasi, R. (2016). Comparison of multistorey cross-laminated timber and timber frame buildings by in situ modal analysis. Constr. Build. Mater. 102, 1009-1017. doi: 10.1016/j.conbuildmat. 2015.09.056

Reynolds, T., Harris, R., Chang, W.-S., Bregulla, J., and Bawcombe, J. (2015). Ambient vibration tests of a cross-laminated timber building.
Soti, Dr. Leonardo Rodrigues, and Evan Schmidt. The authors would like to thank the building owner (reworks Inc.) and Lever Architecture for providing access to the building.

Proc. Inst. Civ. Eng. Constr. Mater. 168, 121-131. doi: 10.1680/coma.14. 00047

Worth, M., Gaul, A., Jager, S., Omenzetter, P., and Morris, H. (2012). "Dynamic performance assessment of a multistorey timber building via ambient and forced vibration testing, continuous seismic monitoring and finite element model updating," in World Conference on Timber Engineering 2012. Auckland, New Zealand.

Conflict of Interest Statement: The authors declare that the research was conducted in the absence of any commercial or financial relationships that could be construed as a potential conflict of interest.

Copyright (C) 2019 Mugabo, Barbosa, Riggio and Batti. This is an open-access article distributed under the terms of the Creative Commons Attribution License (CC BY). The use, distribution or reproduction in other forums is permitted, provided the original author(s) and the copyright owner(s) are credited and that the original publication in this journal is cited, in accordance with accepted academic practice. No use, distribution or reproduction is permitted which does not comply with these terms. 